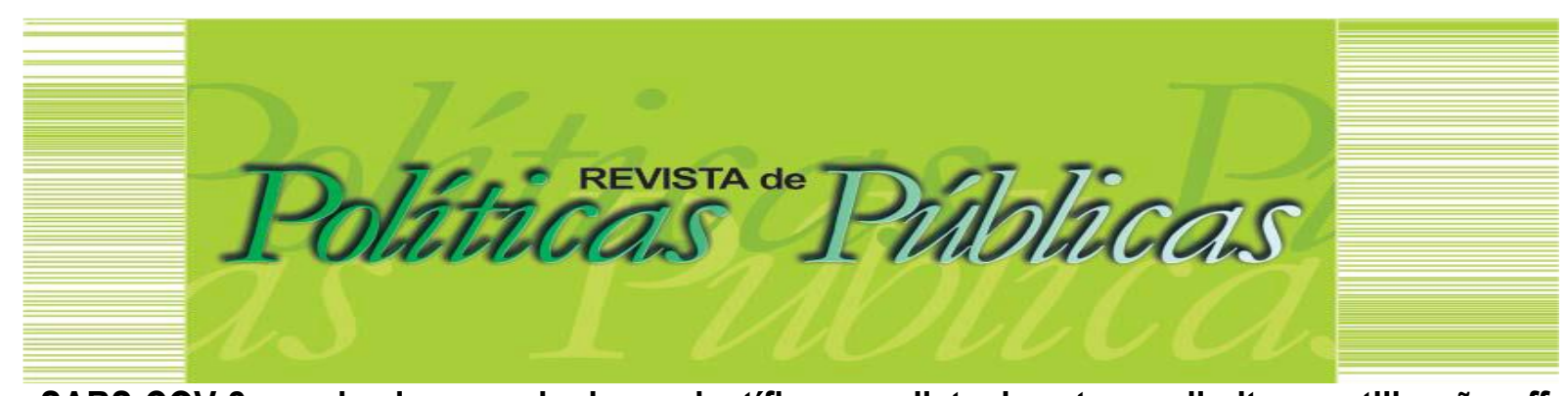

\title{
SARS-COV-2: pandemia, negacionismo científico populista de extrema direita e a utilização off
} label de medicamentos

\author{
Ana Taís Bassani1 \\ Gabriela Fabris² \\ Sergio Simoni Junior ${ }^{3}$
}

\section{Resumo}

A pandemia do SARS-CoV-2, conhecido como novo coronavírus, é uma das maiores crises sanitárias da história. Alguns governos, caracterizados como populistas de extrema direita, adotaram discursos e políticas públicas em prol de um kit de medicamentos que supostamente retardariam a piora clínica de pacientes infectados com o vírus. Este artigo combina análises do âmbito da farmacologia, virologia e ciências humanas para ressaltar a ausência de comprovação científica da eficácia desses medicamentos e as interpretações para o comportamento destas lideranças, notadamente Bolsonaro e Trump, bem como alguns indícios de que esta forma de politização do combate à pandemia implica, direta ou indiretamente, no descumprimento de medidas protetivas e aumento do número de casos de infecção e mortes pela COVID-19.

Palavras-chave: Coronavírus. Populismo. Negacionismo. Hidroxicloroquina. Ivermectina.

\section{SARS-CoV-2: pandemic, extreme right-wing populist scientific negationism and the offlabel use of medicines}

\begin{abstract}
The SARS-CoV-2 pandemic, known as the new coronavirus, is one of the biggest health crisis in history. Some governments characterized as far-right populists, have adopted speeches and public policies in favor of a drug kit that is supposed to slow the clinical worsening of patients infected with the virus. This article combined analyses from the scope of pharmacology, virology and human sciences to highlight the lack of scientific proof for these drugs effectiveness and the interpretations for these leaders behavior, notably Bolsonaro and Trump, as well as some evidence that this kind of politicization in combating the pandemic implies, directly or indirectly, failure to comply with protective measures and an increase in the number of infection cases and deaths by COVID-19.
\end{abstract}

Keywords: Coronavirus. Populism. Negationism. Hydroxychloroquine. Ivermectin.

Artigo recebido em: 21/12/2020 Aprovado em: 27/05/2021 DOI: http://dx.doi.org/10.18764/2178-2865.v25n1p228-244

\footnotetext{
1 Bióloga. Especialista em Qualificação Docente em Ciências da Natureza e Matemática pela Universidade Estadual do Rio Grande do Sul (UERGS). E-mail: anataisbassani@hotmail.com

2 Graduanda em Bacharelado em Políticas Públicas pela Universidade Federal do Rio Grande do Sul (UFRGS). Email: gabriela-fabris@hotmail.com

3 Cientista Político. Doutor em Ciência Política pela Universidade de São Paulo (USP). Professor do Programa de PósGraduação em Políticas Públicas e do Programa de Pós-Graduação em Ciência Política da Universidade Federal do Rio Grande do Sul (UFRGS). E-mail: sergiojr_ssj@yahoo.com.br
} 


\section{INTRODUÇÃO}

A família Coronaviridae é uma família de grandes vírus de RNA que causam infecções respiratórias em humanos e animais.Na década de 60 foram identificados os primeiros coronavírus humanos, e até o momento foi indicada uma série de coronavírus causadores de enfermidades, incluindo o causador da SARS (Síndrome Respiratória Aguda Grave) e da MERS (Síndrome Respiratória do Oriente Médio). (FIOCRUZ, 2020).

O vírus causador da doença denominada COVID-19 é um novo Betacoronavírus (ALI; VIJAYAN, 2020; DUARTE, 2020; NETTO; CORRÊA, 2020), e devido à semelhança genética com 0 vírus causador da SARS (Síndrome Aguda Respiratória Grave), o International Committee on Taxonomy of Viruses o denominou como SARS-CoV-2 (NETTO; CORRÊA, 2020;WHO, 2020).

Biologicamente, os virus caracterizam-se como parasitas intracelulares obrigatórios, sendo necessária a utilização da maquinaria celular de um hospedeiro para sobrevivência e reprodução. O SARS-CoV-2 é um vírus de RNA positivo (CALYet al., 2020), que contém glicoproteínas spikes(S) na superfície viral, formando uma estrutura semelhante a uma "coroa". Estas proteínas são as responsáveis pela ligação do vírus com as enzimas conversoras de angiotensina 2 (ACE2)na superfície externa de uma grande variedade de células humanas, iniciando o ciclo de replicação viral (ALI; VIJAYAN, 2020).

Mutações permitiram que os domínios de ligação ao receptor (RBD)presentes nas proteínas S, possuam alta afinidade com o receptorACE2 (ANDERSEN et al., 2020), o que poderia explicar a facilidade da entrada do vírus (ALI; VIJAYAN, 2020) e grande transmissibilidade da doença, ocasionandoevolução da pandemia mundial. Outra característica importante é a presença de um sítio de clivagem polibásico, localizado na junção das subunidades S1 e S2 da proteína spike, que esclareceria também a infectividade do vírus (ANDERSEN et al., 2020).

As hipóteses mais aceitas pelos cientistas afirmam que 0 início da pandemia se deu em 2019, nos mercados de Wuhan, na China, onde são comercializadas diversas espécies selvagens para consumo. Sequenciamentos do genoma indicariam a similaridade de SARS-CoV-2 de humanos com SARS-CoV-2 de morcegos e pangolins(ANDERSEN et al., 2020).

Ainda, segundo Andersene colaboradores (2020), a origem do coronavírus poderia ser explicada através de uma transferência zoonótica. A seleção natural pode ter ocorrido antes, no hospedeiro, ou depois dessa transferência, nos humanos.

A transmissão entre humanos ocorre pelo contato com superfícies contaminadas e com partículas de saliva expelidas pela boca e nariz de pessoas infectadas (NETTO; CORRÊA, 2020). 
Autoridades mundiais, como a Organização Mundial da Saúde (OMS),têm realizado grandes esforços para conter a disseminação viral, até a fabricação e distribuição em massa de vacina, que apenas se iniciou em alguns países no final do ano de 2020. Todavia, continua sendo necessária a testagem e isolamento dos contatos das pessoas contaminadas, distribuição de insumos hospitalares e aumento da capacidade do sistema de saúde.Além disso, no informe no 15 de 2020 da Sociedade Brasileira de Infectologia, há a recomendação de medidas protetivas como a higienização das mãos, etiqueta respiratória e isolamento físico aliados ao uso massivo de máscaras.

Contudo, alguns governos optaram pela ênfase no uso de fármacos off label, que pode ser definido como o aproveitamento de medicamentos já existentes, prescritos originalmente para o tratamento de outras comorbidades, e que poderiam, em caráter emergencial, ser utilizados para combatera COVID-19 - notadamente a cloroquina/hidroxicloroquina concomitantemente ou não com a azitromicina e ivermectina.Entretanto, a realização de testes clínicos com pacientes é muito importante. Os testes trariam resultados sobre a eficácia dessas drogas, além de determinar a dosagem e posologiaadequadas, toxicidade e possibilidades de interações medicamentosas, evitando prejuízos à saúde dos pacientes que utilizam esses medicamentos.

Neste artigo, combinamos três áreas de conhecimento, a farmacologia, virologia e as Ciências Sociais e Políticas Públicas, para, na primeira seção após esta introdução, apresentar um balanço dos estudos clínicos sobre a eficácia desses medicamentos e analisar a atuação de governos, particularmente no Brasil e nos EUA, que, a despeito da ausência de testes científicos favoráveis, recomendam e implementam programas de compra e fabricação de kits. Na seção seguinte chamamos atenção sobre como essa estratégia se vincula a teses e interpretações recentes sobre a emergência de um populismo de extrema direita em diversos países que se utilizam de disseminação de desinformação pelas redes sociais. No momento da pandemia ganha força a faceta particular do negacionismo científico, e uma de suas consequências, como ressaltamos a partir de outros estudos, é o aumento do número de infecção e mortes pela COVID-19. Por fim, concluímos com uma síntese do artigo, apontando para o momento atual dos embates em torno da vacina.

\section{O MÉTODO CIENTÍFICO NA PRODUÇÃO DE MEDICAMENTOS}

No Brasil, a Lei n 5991/1973 determina que medicamento é o "produto farmacêutico, tecnicamente obtido ou elaborado, com finalidade profilática, curativa, paliativa ou para fins de diagnóstico" (BRASIL, 1973). AAgência Nacional de Vigilância Sanitária (ANVISA) foi criada no ano de 1999 e é o órgão responsável pela Regulamentação da Produção e Comercialização de Medicamentos no país (BRASIL, 1999). 
Em condições distintas de caráter de urgência, como uma pandemia,abusca de candidatos a fármacos perdura por muitos anos.Primeiramente, há a descoberta do composto e sua caracterização. A partir de um candidato a fármaco, são realizados estudos pré-clínicos,que seriam os testes in vitro. Dessa forma, avalia-se o efeito biológico e consegue-se verificar a segurança do medicamento. Posteriormente, são realizados testes em animais não-humanos, como camundongos, coelhos e macacos.Só passam para a fase de pesquisa clínica os medicamentos que não sejam demasiadamente tóxicos para seres humanos (SAID, 2004; ANVISA, 2018; BONELLA et al., 2020).

Na próxima etapa, chamada de Fase clínica, os medicamentos são avaliados em três fases distintas. A Fase I inicia com seres humanos considerados saudáveis, em número reduzidocerca de 20 a 100 pessoas- na qualidade de voluntários (SAID, 2004; BONELLA et al., 2020). Já na Fase II, os pacientes possuem determinada comorbidade e os ensaios verificam a atividade farmacológica da substância. Cerca de 100 a 200 indivíduos são convocados para o estudo, averiguando a segurança medicamentosa (SAID, 2004).

Enquanto a Fase III configura-se como mais ampla. Sãono mínimo 800 pacientes, em vários centros e populações diferenciados e a pesquisa visa identificar as reações colaterais mais recorrentes. Quando aprovado em todas as fases, o medicamento pode ser registrado junto à ANVISA (SAID, 2004).

3 AS 4-AMINOQUINOLINAS: a Hidroxicloroquina (HCQ)e a Cloroquina (CQ)

A cloroquina e a hidroxicloroquina são compostos semelhantes nos aspectos relacionados às indicações de uso, alvos de ação e toxicidade. A diferença estrutural dos fármacos dá-se pela presença de um grupo $\mathrm{OH}$ (hidroxila) na hidroxicloroquina, além de que esta é administrada como sulfato, enquanto a cloroquina como fosfato (KHUROO; SOFI; KHUROO, 2020).

As discussões relativas à cloroquina e hidroxicloroquina iniciaram na década de 2000 , com estudos em laboratório para tratar o surto daSARS,porém, não houve progressão para estudos clínicos. Com o surgimento do surto de SARS-CoV-2, no final de 2019, novos testes in vitroiniciaramcom a HCQ e CQ, demonstrando a inibição viral (ZHAN et al., 2020).

Os mecanismos envolvidos na ação destes fármacos envolveriam duas possibilidades: a primeira é que haveria uma glicosilação do receptor ACE2, alterando seu sítio de ligação com a proteína spike, interferindo na afinidade do vírus com a célula hospedeira, impedindo a sua entrada (SINGH et al., 2020).A segunda possibilidade é de que as drogas poderiam alterar $0 \mathrm{pH}$ dos endossomos e lisossomos, atrapalhando a fusão do SARS-CoV-2 com as células hospedeiras. Este 
processo foi observado in vitro, em linhagens celulares VERO (KHUROO; SOFI; KHUROO, 2020; HOFFMANN et al., 2020).

Apesar dessas evidências observadas in vitro e a utilização off label desses fármacos, a mesma eficácia não foi verificada em ensaios clínicos (ZHAN et al.,2020;KHUROO; SOFI; KHUROO, 2020; TAKAHASHI et al., 2020). Um estudo observacional de coorte, multicêntrico e retrospectivo realizado por Rosenberg e colaboradores,avaliou1438 pacienteshospitalizados.Destes, $51,1 \%$ ou seja, 735 pacientes receberam uma combinação de HCQ eazitromicina; 18,8\% (271) receberam HCQ sem associações, 15,4\% (221) não receberam nenhumfármaco e, finalmente, 14,7\%, (211) pacientes receberam azitromicina. A partir dos resultados obtidos não foi possível observar diferenças significativas na mortalidade intra-hospitalarpara pacientes que receberam HCQ eazitromicina, $\mathrm{HCQ}$ sem associações ou azitromicina (ROSENBERG et al., 2020).

Ademais, estudos randomizados, multicêntricos e controlados têm sido realizados, como 0 "Coalizão COVID-19 Brasil", corroborando com esses resultados. Neste estudo, foram observados pacientes internados com Covid-19 em55 hospitais do país, a fim de verificar se a HCQ combinada ou não com a azitromicina promoveria melhora clínica em pacientes com coronavírus, sintomáticos leves e moderados, após 15 dias de internação hospitalar. Verificou-se que não houve diferença significativa no resultado do estado clínico entre os grupos que receberam hidroxicloroquina mais azitromicina, tratamento padrão ou hidroxicloroquina isolada (CAVALCANTI et al., 2020).

O sucesso da CQ e HCQ contra o SARS-CoV-2 em laboratório, mas nãoem estudos clínicos da COVID-19 poderia ser explicado por duas enzimas: a catepsina $L$ e a TMPRSS2. As células VERO, muito utilizadas em estudos in vitro, são células renais de macaco verde africano. Necessitam da proteasecatepsina $\mathrm{L}$, dependente de $\mathrm{pH}$ ácido para que o coronavírus as infecte. $\mathrm{HCQ}$ e $\mathrm{CQ}$ tornam o pH endossomal alcalino, desativando essa enzima, e evitando que o SARS-CoV-2 entre na célula. Todavia,quandoesses fármacos foram utilizados em células que podem simular modelos respiratórios, conhecidas como células de pulmão humano Calu-3, o SARS-CoV-2 consegue entrar livremente.Isso porque elas possuem pouca catepsina $L$ e utilizam uma outra via, chamada de serina protease transmembranar 2 (TMPRSS2). A TMPRSS2 não é dependente de pH, então a CQ e HCQ não surtem nenhum efeito sobre ela. Dessa forma, em consonância com os resultados obtidos em estudos clínicos,esses medicamentos não exercerão atuação antiviral no hospedeiro(KHUROO; SOFI; KHUROO, 2020; HOFFMANN et al., 2020).

Quando utilizados para doenças autoimunes como a artrite reumatoide e lúpus, $\mathrm{HCQ}$ e CQ são medicamentos relativamente seguros (TAKAHASHI et al., 2020). Porém, efeitos adversos da HCQ e CQ no tratamento da COVID-19 têm sido observados nos pacientes, como arritmia cardíaca, 
prolongamento QT, parada cardíaca e lesões hepáticas (CAVALCANTI et al., 2020; ROSENBERG et al. 2020).

\section{A IVERMECTINA}

A ivermectina é um medicamento que possui conhecida ação antiparasitária e seu possível efeito antiviral tem sido avaliado em diversos estudos, analisando seus efeitos sobre a infecção com Zika, Dengue e Febre Amarela (CHACCOUR et al., 2020).Calye colaboradores(2020) observaram que em células VERO/hSLAM infectadas com SARS-CoV-2, ocorreu a redução de $\sim 5000$ vezes do RNA viral, in vitro, após a adição de $5 \mu \mathrm{M}$ de ivermectina. Porém, segundo Schmith, Zhou e Lohmer (2020),os resultados observados ocorreram apenas em doses elevadas do medicamento. Em humanos, as concentrações plasmáticas e pulmonares alcançadas após a administração de doses seguras do medicamento são em valores muito menores do que o utilizado no estudo, portanto ensaiosexitosos com seres humanos seriam pouco prováveis e poderiam ser neurotóxicos.

Em suma, todos esses achados in vitro trouxeram grandes discussões para o uso incontroladooff label -kits"COVID-19", contendo cloroquina e hidroxicloroquina, em conjunto com azitromicina, ivermectina,zinco evitamina $\mathrm{D}$, que não se mostraram clinicamente aceitáveis.

Até a fabricação e a distribuição de vacinas, a principal medida passível de contenção à disseminação da pandemia é o isolamento físico. Evidente que esta determinação implica em imensos custos (econômicos, sociais, psicológicos) e os governos variaram nos tipos de resposta adotadas. No entanto, alguns governantes, em particular, se caracterizaram na defesa da restrição mínima da atividade econômica, em parte com 0 argumento de que o "tratamento precoce" com os medicamentos acima citados possibilitaria às pessoas continuarem com seus trabalhos presenciais, supostamente prevenindo formas graves da doença.

Minimizando ou ignorando os testes e as recomendações científicas, esta ideologia política se soma a outros elementos que analistas e teóricos caracterizam como constituindo a emergência do populismo de extrema direita.

\section{O POPULISMO DE EXTREMA DIREITA E SUA RELAÇÃO COM O NEGACIONISMO}

Países tão diversos como Estados Unidos, Turquia, Polônia, Índia, Hungria e Brasil assistiram nos últimos anos à ascensão de lideranças nacionais de extrema direita, caracterizados por ultraconservadorismo, nacionalismo exacerbado, ataque aos direitos de minorias, e comunicação direta 
via redes sociais, contornando os grandes órgãos de imprensa, não raras vezes com desinformação e fakenews.

Não temos intenção de adentrar no pantanoso e disputado terreno de definição e explicação sobre o populismo em geral ou o populismo de extrema direita, em particular ${ }^{1}$.Uma das características comuns é sua emergência em contextos de "fracasso das instituições sociais e políticas existentes para limitar e regular os sujeitos políticos dentro de uma ordem social relativamente estável", sendo ele, "um modo de identificação característico de tempos de instabilidade" (PANIZZA, 2005).

Assim, os eventos ocorridos no Brasil contemporâneo têm favorecido o aparecimento do populismo, notadamente as grandes crises políticas, econômicas e sociais que se iniciam no final de 2014 e se expressam na recessão econômica, no aumento da pobreza e desigualdade, no impeachment de Dilma Rousseff, nas grandes manifestações de rua e nas operações da Lava-Jato. Nas palavras de Scott $(2019$, p.13) após as eleições de 2018:

\begin{abstract}
A recente eleição do Brasil espelha a crise da política eleitoral em outros países. A onda populista prospera com base em desinformação, mentiras descaradas, notícias falsas e boatos. Curiosamente, tem sido o WhatsApp, ao invés do Facebook ou Twitter, que agora é o principal canal para o acalorado debate político no Brasil. O WhatsApp não é filtrado. Também é interessante notar que a mídia impressa no Brasil está em crise. As comparações são sempre perigosas, mas Trump, embora em parte correto sobre criticar as "notícias falsas", também fez o seu melhor para pintar a mídia como desconfiada e ilegítima. Bolsonaro adotou uma linha ainda mais dura contra a liberdade de imprensa. (Tradução livre).
\end{abstract}

Desde sua pretérita carreira política como deputado federal, passando pela campanha eleitoral de 2018 e seu primeiro ano de seu governo, Jair Bolsonaro demonstra diversos sinais dessa caracterização, exclamando discursos xenofóbicos, preconceituosos, racistas, e, homofóbicos; cerceando a imprensa e ocultando informações de interesse público dos sites de transparência do governo; defendendo a militarização da sociedade; criando a ideia de um inimigo nacional - 0 "comunismo"; fomentando e apoiando protestos contra o Supremo Tribunal Federal e o Congresso; celebrando publicamente o golpe que deu origem à ditadura civil militar no Brasil (1964 - 1985), homenageando os agentes de tortura do período.

Uma dimensão particular dessa "ideologia política" que ganhou consequências importantes em 2020 foi a negação da importância do conhecimento técnico científico ${ }^{2}$.Nos últimos tempos tornou-se crescente a exposição de grupos autodenominados "terraplanistas" que contestam a visão científica de que a Terra tem forma globular (ALVIM, 2020). Essa disposição ganha contornos mais consequentes no momento da pandemia, com a descrença nas medidas preconizadas pela OMS e a defesa de medicamentos sem comprovação clínica.

É importante notar que existem diferenças importantes entre os governos caracterizados como populistas de direita, que se aplicam também nas respostas que deram no combate à pandemia. 
A Hungria, por exemplo, do primeiro-ministro Viktor Orbán, adotou medidas fortemente restritivas, por meio da delegação de poderes ao chefe do Executivo (UOL, 2020). De outro lado, alguns governos comandados por líderes de esquerda, como Manuel López Obrador, no México (GAÚCHA ZH, 2020) e Daniel Ortega na Nicarágua (MAISONNAVE, 2020), minimizaram a importância do distanciamento físico, das restrições às atividades econômicas e das mortes causadas pela COVID-19.

No entanto, os governos federais de Brasil e EUA, expoentes da onda populista de extrema direita, se destacaram pelo uso da desinformação como arma política no combate ao coronavírus. Segundo Hollyer, Rosendorff e Vreeland (2019), a democracia tem menos probabilidade de sobreviver em um ambiente caracterizado pela desinformação e por "notícias falsas", pois quando os eleitores são mal informados, existe a possibilidade de levar à eleição governos incompetentes e corruptos.Falasde Jair Bolsonaro como: "Agora vem aquela historinha do passado: 'Ah, não tem comprovação científica'. E daí? [...] Qual alternativa? Não tinha alternativa, toma hidroxicloroquina ou não toma nada." e "Deus foi tão abençoado que nos deu até a hidroxicloroquina", são comuns, e demonstram o negacionismo científico explícito presente nos discursos presidenciais, validando-o como importante ferramenta de manobra política da extrema direita. Um levantamento averiguou que os eleitores identificados por um posicionamento político de direita foram diminuindo o apoio ao isolamento social conforme foi se dando o agravamento da pandemia no Brasil (PEREIRA; MEDEIROS; BERTHOLINI, 2020).

Revelando um mimetismo de estratégias, tais falas se tornaram comumente utilizadas após o ex-presidente dos Estados Unidos, Donald Trump, defender publicamente a liberação da hidroxicloroquina pelos órgãos de saúde pública, sugerindo a combinação com 0 antibiótico azitromicina para prevenir e tratar a COVID-193. No dia 18 de maio de 2020, em um de seus pronunciamentos, Trump declarou: "Eu tomo, muitos médicos tomam. Espero não precisar tomar, espero que encontrem alguma resposta (contra a COVID-19), mas acho que as pessoas devem ser autorizadas (a tomar)." As declarações pessoais de Trump iam contra a recomendação do governo.Em março,a FDA (Food and Drug Administration) - agência reguladora de alimentos e medicamentos nos EUA - havia autorizado o uso emergencial da hidroxicloroquina - recomendada para tratar lúpus e malária através do Programa Nacional de Controle da Malária (PNPCM) - apenas para um número limitado de pessoas internadas por COVID-19. Apenas 4 meses depois, a FDA revogou a autorização de uso de emergência para hidroxicloroquina e cloroquina, com a justificativa de que os medicamentos não se mostraram seguros e eficazes contra a doença COVID-19 (FERRARI, 2020).

Em 29 de julho de 2020, Trump afirmou que a cloroquina só foi criticada porque ele próprio a havia recomendado, retomando assim, a propaganda de incentivo ao uso pela população. 0 médico responsável por coordenar as ações governamentais frente à pandemia, Anthony Fauci, 
declarou em resposta: "Sabemos que todos os bons estudos - e por bons estudos eu quero dizer estudos controlados randomizados nos quais os dados são contundentes e críveis - mostraram que a hidroxicloroquina não é eficiente no tratamento da COVID-19", contrariando assim, a fala "próCloroquina" de Trump. Apesar de ter afirmado que fizera uso profilático da hidroxicloroquina, o expresidente Donald Trump testou positivo, em 2 de outubro, para o coronavírus (FERRARI, 2020), assim como Bolsonaro, em julho, sendo internado em um hospital militar menos de 24h após a confirmação de sua contaminação. De acordo com Sean P. Conley (médico chefe da Casa Branca), o tratamento doex-presidente norte-americano foi feito a partir da injeção de oito gramas do REGN-COV2 - que utiliza um coquetel de anticorpos monoclonais - além do antiviral remdesivir e outros medicamentos como dexametasona, zinco, vitamina D, famotidina, melatonina e aspirina (LAVADO, 2020) sem qualquer intervenção de hidroxicloroquina, até então defendida por Trump.

Apoiador de Trump, o Presidente Jair Bolsonaro anunciou que o Exército Brasileiro passaria a produzir a cloroquina para o tratamento contra a COVID-19. 0 anúncio foi feito formalmente em uma coletiva de imprensa por Denizar Vianna, Secretário de Ciência e Tecnologia do Ministério da Saúde. As falas presidenciais "pró cloroquina" de Trump e Bolsonaro provocaram, inicialmente, uma imensa procura pelo medicamento nas farmácias, tanto norte-americanas, quanto brasileiras, de modo que a Agência Nacional de Vigilância Sanitária (ANVISA) teve que passar a restringir a venda no Brasil, exigindo prescrição médica (MOTA, 2020). De acordo com o Sindicato da Indústria de Produtos Farmacêuticos (Sindusfarma), o consumo da cloroquina cresceu $358 \%$ durante a pandemia (CAMPOREZ, 2020).

Em uma pesquisa feita pela Associação Paulista de Medicina (APM) entre os dias 25 de junho e 2 de julho, com uma amostra de 1984 médicos atuantes no país, verificou-se que 69,2\% acreditam que as notícias falsas levam a população a minimizar o problema e a não observar as recomendações de isolamento físico e higiene; 48,9\% afirmam ter a relação com paciente comprometida, já que os pacientes, conforme José Luiz Gomes do Amaral (Presidente da APM), influenciados pelas fakenews de remédios milagrosos, se negam a realizar exames, a receber diagnósticos, e a seguir orientação médica, solicitando apenas a prescrição do medicamento "miraculoso", 69\% manifestaram ansiedade; $63,5 \%$, estresse; e 49\%, exaustão emocional (PEREIRA; MEDEIROS; BERTHOLINI, 2020).

A defesa do uso profilático da cloroquina pelo presidente Jair Bolsonaro, com um perceptível viés político, reforça essa demanda, colocando em risco a saúde da população, já que nem mesmo o Conselho Federal de Medicina (CFM) - que havia autorizado o uso da hidroxicloroquina nos casos mais brandos de COVID-19 - defende o uso de maneira preventiva (LIMA; CARDIM, 2020). 
Indo contra a ciência, o Governo Federal recomenda que os estoques de cloroquina/hidroxicloroquina sejam priorizados para pacientes com COVID-19. Todavia, essa política é geradora de diversas barreiras aos portadores das doenças para as quais o medicamento é indicado, como Lúpus Eritematoso Sistêmico (LES), Artrite Reumatoide e Lúpus Cutâneo.Os pacientes que apresentam estas enfermidades dependem do uso contínuo destes medicamentos, e a busca desenfreada por eles pode acabar causando desabastecimento, prejudicando aqueles que realmente necessitam deles para tratamento.Adversamente, o próprio Conselho Nacional de Saúde tentou impedir que esses medicamentos fossem utilizados para fins adversos de sua bula, pela não comprovação científica de sua eficácia (BRASIL, 2020).

Outro estudo desenvolvido por Fernandes e colaboradores (2020) corrobora para a proposição de que Bolsonaro como "garoto propaganda" da cloroquina esteja causando mais mortes, principalmente, as de seus apoiadores. A pesquisa considerou as ocasiões em que Bolsonaro minimizou - publicamente - a pandemia, através de seus discursos negacionistas, possibilitando verificar uma queda significativa nas taxas de isolamento físico, e um aumento no número de mortes, proporcionalmente, nos municípios em que ele teve mais votos nas eleições de 2018. Assim, nos locais que Bolsonaro teve mais eleitores, menor foi a prática do isolamento físico, e maior o número de óbitos por COVID-19 (FERNANDES et al., 2020).

Algumas suposições de irregularidades também apareceram no Brasil, de maneira que 0 subprocurador-geral do Ministério Público, Lucas Furtado, junto ao Tribunal de Contas da União, solicitou a instauração de um inquérito - com o objetivo de averiguar se ocorreu superfaturamento na fabricação de cloroquina pelo Laboratório Químico e Farmacêutico do Exército (LQFEX), de modo a responsabilizar o presidente por ordenar o aumento expressivo na produção dos comprimidos - cerca de 3,2 milhões produzidos em 2020 - , mesmo depois de proibidos pela Organização Mundial da Saúde (OMS) no tratamento da COVID-19. Débora Melecchi, do Conselho Nacional de Saúde (CNS) afirma que o Exército aumentou 100 vezes a produção de cloroquina desde o início da pandemia, sendo gasta uma quantia exorbitante de dinheiro - sem licitação - para a compra dos insumos (PONTES, 2020). Por meio da Lei de Acesso à Informação, foi possível verificar que apenas duas empresas foram contatadas para fornecer orçamento referente à compra da cloroquina, sendo que, segundo a Anvisa, mais de 10 mil empresas possuem licença para importar medicamentos no Brasil (TOLEDO, 2020).

O Centro de Comunicação Social do Exército Brasileiro, ao ser questionado acerca do elevado valor gasto na compra de insumos através da empresa Sul Minas para a fabricação de Cloroquina, defendeu o contrato da compra, mesmo tendo pago $167 \%$ a mais se comparado ao contingente comprado - da mesma companhia - dois meses antes. O Laboratório Químico Farmacêutico do Exército afirmou não possuir informações sobre os preços pagos pela importação dos 
insumos pela Sul Minas, justificando que não cabe ao laboratório ter tais informações, mas sim "fazer a contratação e aquisição de materiais com o melhor preço ou técnica baseada em ampla pesquisa de preços no mercado, conforme a Lei n 8.666/93." Contraditoriamente, o LQFEX já havia gasto, até 15 de setembro de 2020, R\$1,1 milhão na fabricação de cloroquina (TOLEDO, 2020).

Como visto, o posicionamento do Governo acerca da cloroquina esteve repleto de divergências e contradições. Inicialmente, houve a demissão do Ministro da Saúde Luiz Henrique Mandetta, por discordar do presidente sobre o uso do medicamento e sobre o isolamento vertical exclusivo para o grupo de risco. O mesmo ocorreu com o médico oncologista Nelson Teich, que deixou o comando do Ministério da Saúde menos de um mês no cargo, após o presidente autorizar, por meio de um decreto, a abertura de salões de beleza, barbearias e academias. 0 posicionamento institucional do Ministério foi novamente alterado sob o comando de Eduardo Pazuello, terceiro ministro da Saúde do governo Bolsonaro, que logo após a posse, em maio, já apresentou novas diretrizes para o uso do medicamento, incluindo o fornecimento de cloroquina no Programa Aqui Tem Farmácia Popular, juntamente com o antibiótico azitromicina, que serviria como tratamento precoce do coronavírus, formando assim o "kit Covid", em um plano que pretendia reembolsar farmácias conveniadas para distribuir gratuitamente os medicamentos (SABINO; BEHNKE; SOARES, 2020).

Em maio de 2020, o Centro de Operações de Emergência (COE) já informava que havia um estoque de 1,4 milhões de comprimidos de cloroquina - devido à recusa de alguns estados no recebimento do medicamento. Ademais, com os 3 milhões de comprimidos enviados por Trump e pela farmacêutica Sandoz, a quantidade de comprimidos de cloroquina em estoque aumentou para mais de 2,5 milhões em dezembro. No entanto, o plano do governo não engloba, na composição do "kit Covid", os comprimidos em estoque, de modo que o Ministério Público Federal (MPF) foi obrigado a fazer uma intervenção, após a Secretaria Executiva do Ministério da Saúde receber ofícios, por procuradores de diversos estados, questionando o plano do governo de destinar $\mathrm{R} \$ 250$ milhões, ainda sem explicações por parte do secretário executivo da pasta, Élcio Franco, para o "kit" (ORTEGA; MOTTA, 2020).Com o valor previsto para distribuir o "kit" seria possível - através da compra da vacina da Universidade de Oxford e do laboratório AstraZeneca, por exemplo - imunizar cerca de 7 milhões de pessoas (VARGAS, 2020).

Algumas interpretações e explicações podem ser levantadas para as atitudes de Trump e Bolsonaro. Uma delas ressalta a dimensão político-eleitoral. Crises econômicas tendem a prejudicar a avaliação dos governos e dificultar a manutenção de seus postos, por isso a relutância em adotar medidas de restrição às atividades comerciais. Este aspecto se aplica particularmente ao caso norteamericano, pois em novembro do ano pandêmico, Trump disputaria e (perderia) a reeleição 4 . Outras abordagens, mais interpretativas, chamam a atenção para a manifestação da necropolítica, conceito 
formulado por Mbembe (2018), referente às formas contemporâneas que subjugam a vida ao poder da morte. Em entrevista a um programa televisivo, o presidente Bolsonaro declarou: "Alguns vão morrer? Vão morrer. Lamento, é a vida. Não pode parar uma fábrica de automóveis porque tem mortes no trânsito". Em que pesem as diferentes abordagens, é essencial frisar que o negacionismo é uma tática política, uma estratégia deliberada de polarização em busca de dividendos políticos.

\section{CONSIDERAÇÕES FINAIS}

Em tempos de pandemia, deve-se ouvir e seguir as recomendações dadas pelos cientistas e autoridades sanitárias, como a Organização Mundial da Saúde. Diversos estudos clínicos com métodos científicos bem delineados já evidenciaram que a ivermectina, hidroxicloroquina e cloroquina combinadas ou não com a azitromicina não combatem o coronavírus. Líderespolíticosque negam os avanços da ciência acabam confundindo a população com seus discursos,levando parte dela a acreditar que o tratamento precoce constituído de uma espécie de kit de medicamentos contra a COVID-19 evitaria muitas mortes - adotando políticas equivocadas, em detrimento do investimento na testagem em massa, no isolamento dos contatos das pessoas positivadas para a COVID-19 e em parcerias com instituições de pesquisa para fortalecer os estudos, compra e aplicação de vacinas seguras e eficazes.

Sabe-se que o sistema de saúde brasileiro só não colapsou,porque houve um esforço desde 0 início da pandemia no país - por parte dos governos municipais e estaduais para que a população fizesse a quarentena, e epidemiologicamente, achatasse a curva de transmissão da doença.

De acordo com Barberia e Goméz (2020), esses governos incrementaram o número de UTIS para atender casos graves da doença e geriram leitos para que todos recebessem atendimento, mesmo que tivesse que ser transferido para outra cidade. Em contrapartida, o populismo de extrema direita, representado pelo presidente do Brasil, utilizava jargões como "É só uma gripezinha", minimizando a COVID-19 e efetivando um general para assumir o Ministério da Saúde (PONCE, 2020).

Ultrapassado o fatídico número de mais de 440 mil mortes por COVID-19 notificadas no país no final de maio de 2021, necessitamos de um planejamento de imunização nacional, utilizando as diversas vacinas que têm demonstrado um bom percentual de eficácia nas últimas etapas dos estudos clínicos que foram realizados e devidamente regulamentadas pela ANVISA. Amplos investimentos na produçãoe compra dessas vacinas, além dos insumos utilizados para sua aplicação, como seringas, agulhas, algodão e equipamentos de proteção individual aos profissionais da saúde, tornam-se urgentemente necessários para conter a disseminação viral. 
No final de 2020, Bolsonaro reforçou a posição do negacionismo científico, questionando a eficácia e a importância da vacinação. Algumas evidências apontam que parte da população acompanha as opiniões do presidente, enquanto governos subnacionais e o Judiciário atuam na produção e compra de vacinas e no reforço do arcabouço jurídico das campanhas. Até quando?

\section{REFERÊNCIAS}

ALI, A., VIJAYAN, R. Dynamics ofthe ACE2-SARS-CoV-2/SARS-CoVspikeprotein interface revealuniquemechanisms. Sci $\operatorname{Rep~10,~} 14214$ (2020). https://doi.org/10.1038/s41598-020-71188-3.

ALVIM, M. Quem são e o que pensam os brasileiros que acreditam que a Terra é plana.BBC, 2020.Disponível em: https://www.bbc.com/portuguese/brasil-41261724 Acesso em: 18 dez. 2020.

ANDERSEN, K. G., RAMBAUT, A., LIPKIN, WI et al. The proximal origin of SARS-CoV-2. Nature Medicine. 26, 450-452(2020). https://doi.org/10.1038/s41591-020-0820-9.

ANVISA- Agência Nacional de Vigilância Sanitária. Registro de novos medicamentos: saiba o que é preciso. 01 nov. 2018. ANVISA. Disponível em: http://portal.anvisa.gov.br/noticias/-

lasset_publisher/FXrpx9qY7FbU/content/registro-de-novos-medicamentos-saiba-o-que-epreciso/219201 Acesso em: 25 set. 2020.

BARBERIA, L. G.\& GÓMEZ, E. J. Political and institutional perils of Brazil's COVID-19 crisis. The Lancet.Vol 396, ISSUE 10248, p. 367-368. https://doi.org/10.1016/S0140-6736(20)31681-0.

BONELLA, A. E., ARAUJO, M. de; DALL'AGNOLL, D. (2020). Bioética em tempos de pandemia: Testes clínicos com Cloroquina para tratamento de COVID-19. Veritas(Porto Alegre), 65(2), e37991. https://doi.org/10.15448/1984-6746.2020.2.37991.

BRASIL. Lei n. ${ }^{0}$ 5991, de 17 de dezembro de 1973. Dispõe sobre o controle sanitário do comércio de drogas, medicamentos, insumos farmacêuticos e correlatos, e dá outras providências. Brasilia: MS, 1973. Disponível em http://www4.planalto.gov.br/legislacao. Acesso em: 25 set. 2020.

BRASIL. Lei n 9.782, de 26 de janeiro de 1999. Define o Sistema Nacional de Vigilância Sanitária, cria a Agência Nacional de Vigilância Sanitária, e dá outras 12 providências. Disponível em: http://www.planalto.gov.br/ccivil_03/leis/L9782.htm. Acesso em 26 set. 2020.

BRASIL. Conselho Nacional de Saúde (2020). Disponível em: http://conselho.saude.gov.br/ultimasnoticias-cns/1323-cns-recomenda-ao-ministerio-da-saude-plano-de-abastecimento-de-cloroquina-parapacientes-com-doencas-cronicas-e-patologias Acesso em: 4 out. 2020.

CALY L., DRUCE J., CATTON M., JANS D., KM W., 2020. The FDA-approved Drug Ivermectin inhibits the replication of SARS-CoV-2 in vitro. Antiviral Res. Disponivel em: https://www.sciencedirect.com/science/article/pii/S0166354220302011. 
CAMPELLO D., ZUCCO C. 0 jogo dos dois erros. Por que Bolsonaro se equivoca ao minimizar a pandemia e ao tentar se eximir da crise econômica. 2020. Disponível em:

https://piaui.folha.uol.com.br/materia/o-jogo-dos-dois-erros/. Acesso em: 17 dez. 2020.

CAMPOREZ, P. Quem são os empresários que ganham com a cloroquina no Brasil.Estadão,2020. Disponível em: https://politica.estadao.com.br/noticias/geral,quem-sao-os-empresarios-que-ganhamcom-a-cloroquina-no-brasil,70003360677. Acesso em: 6 dez. 2020.

CAVALCANTI A.B., ZAMPIERI F.G., ROSA R.G., et al. Hydroxychloroquine with or without Azithromycin in Mild-to-Moderate Covid-19. The New England Journal ofMedicine. (2020) DOI: 10.1056/NEJMoa2019014.

CHACCOUR, C., HAMMANN, F., RAMÓN-GARCÍA, S.; RABINOVICH, N. R. (2020). Ivermectin and COVID-19: Keeping Rigor in Times of Urgency. The American journal of tropical medicine and hygiene, 102(6), 1156-1157. https://doi.org/10.4269/ajtmh.20-0271.

DUARTE, P.M. COVID-19: Origem do novo coronavírus. Brazilian Journal of Health Review. v.3, n.2, p.3585-3590. mar/apr, 2020. DOl:10.34119/bjhrv3n2-187.

FERNANDES, I.; ALMEIDA LOPES FERNANDES, G.; FERNANDES, G.; SALVADOR, P.I. Ideology, Isolation, andDeath. An Analysis of the Effects of Bolsonarism in the COVID-19 Pandemic (Julho 17, 2020). Disponível em SSRN:

https://ssrn.com/abstract=3654538orhttps://dx.doi.org/10.2139/ssrn.3654538.

FERRARI, M. Após tomar hidroxicloroquina para prevenção, Trump é diagnosticado com Covid19. CNN BRASIL, 2020. Disponível em: https://www.cnnbrasil.com.br/internacional/2020/10/02/apostomar-hidroxicloroquina-para-prevencao-trump-e-diagnosticado-com-covid-19. Acesso em: 6 dez. 2020.

FIOCRUZ.Fundação Oswaldo Cruz, Ministério da Saúde, Brasil.2020. Disponível em: http://www.invivo.fiocruz.br/cgi/cgilua.exe/sys/start. $h$ tm?infoid=1438\&sid=8.

GAÚCHA ZH. Na contramão, presidente mexicano pede beijos, abraços e nada de quarentena. GAUCHA ZH, 2020. Disponível em: https://gauchazh.clicrbs.com.br/mundo/noticia/2020/03/nacontramao-presidente-mexicano-pede-beijos-abracos-e-nada-de-quarentenack86ixpy901jo0109wmm76d8l.html Acesso em 18 dez. 2020.

HAWKINS, K. A., KALTWASSER R. C. (2017). The ideational aprroach to populism. Latin American Research Review, 52 (4), 513-528. DOI: http://doi.org/10.25222/larr.85.

HOFFMANN, M., MÖSBAUER, K., HOFMANN-WINKLER, H. et al. Chloroquine does not inhibit infection of human lung cells with SARS-CoV-2. Nature (2020). https://doi.org/10.1038/s41586-0202575-3.

HOLLYER, J. R.; ROSENDORFF, P. B.; VREELAND, J. R. Fake news is bad news for democracy.The Washington Post. 2019. Disponível em:

https://www.washingtonpost.com/politics/2019/04/05/fake-news-is-bad-news-democracy/ Acesso em: 17 dez. 2020.

INFORME DA SOCIEDADE BRASILEIRA DE INFECTOLOGIA SOBRE O NOVO CORONAVÍRUS N 15: uso de medicamentos para covid-19. 2020. Disponível em: https://infectologia.org.br/wp- 
content/uploads/2020/07/Informe-15-uso-de-medicamentos-para-covid-19.pdf. Acesso em: 18 dez 2020.

KHUROO, M.S., SOFI A. A, KHUROO M. Chloroquine and hydroxychloroquine in coronavirus disease 2019 (COVID-19). Facts, fiction \& the hype. A critical appraisallnt. J. Antimicrob. Agents (2020), Sep; 56(3): 106101.https://doi.org/10.1016/j.jantimicag.2020.106101.

LACLAU, E. A Razão Populista. São Paulo: Três Estrelas, 2013.

LAVADO, T. Hospital, sim; cloroquina, não: o tratamento de Trump contra COVID-19.Exame,2020. Disponível em: https://exame.com/ciencia/tratamento-de-trump-contra-covid-19-nao-inclui-cloroquina/. Acesso em: 6 dez. 2020.

LEVITSKY, S., ZIBLATT, D. Como as democracias morrem. São Paulo: Ed. Zahar, 2018.

LIMA, B.; CARDIM, M. E. Médicos são pressionados por pacientes para receitar cloroquina.

Correio Braziliense, 2020. Disponível em:

https://www.correiobraziliense.com.br/app/noticia/brasil/2020/07/09/interna-brasil,870605/medicos-saopressionados-por-pacientes-para-receitar-cloroquina.shtml. Acesso em: 17 dez. 2020.

MAISONNAVE, F. Sumiço de ditador e suspeita de maquiagem da pandemia ligam alerta na Nicarágua.FolhaUol, 2020. Disponível em: https://www1.folha.uol.com.br/mundo/2020/04/sumico-deditador-e-suspeita-de-maquiagem-da-pandemia-ligam-alerta-na-nicaragua.shtml Acesso em: 18 dez. 2020.

MBEMBE, A. Necropolítica. 3. ed. São Paulo: n-1 edições, 2018. 80 p.

MORAIS J.A., COSTA A. L.V., BERNARDI A. J. B. Populismo, popularização política e a pandemia do coronavírus: Donald Trump e a opinião pública dos Estados Unidos. Revista Debates, Porto Alegre, v.14, n 3, p. 126-149. set-dez 2020. Disponível em: https://seer.ufrgs.br/debates/article/view/109155/59702 Acesso em $18 \mathrm{dez}$. 2020https://doi.org/10.22456/1982-5269.109155.

MOTA, C. V. Coronavírus: o que a Ciência diz sobre o uso da cloroquina contra a Covid-19. BBC, 2020. Disponível em: https://www.bbc.com/portuguese/geral-52067244. Acesso em: 5 dez. 2020.

NASCIMENTO, K. L. 2018. O populismo na perspectiva de Ernesto Laclau: uma alternativa para à esquerda? Revista Estudos Políticos - UFF. Rio de Janeiro. v.9. n. 1, pp. 32-48. 2018. https://doi.org/10.22409/rep.v9i17.39849.

NETTO, R. G. F, \& do N. CORREAA, J. W.Epidemiologia do surto de doença por coronavírus (COVID19). DESAFIOS - Revista Interdisciplinar Da Universidade Federal Do Tocantins, 7(Especial-3), 1825.2020https://doi.org/10.20873/uftsuple2020-8710.

NORRIS, P.; RONALD, I. (2019) Cultural backlash: Trump, Brexit and authoritarian populism. Cambridge: Cambridge University Press. DOI://10.1017/9781108595841.

ORTEGA, P.; MOTTA, R. Procuradores cobram explicações sobre "kit covid" de R $\mathbf{2 5 0}$ milhões. 2020. Disponível em: https://gauchazh.clicrbs.com.br/saude/noticia/2020/12/procuradores-cobramexplicacoes-sobre-kit-covid-de-r-250-milhoes-ckirn9fwr005501iicizsea5s.html. Acesso em: 16dez. 2020. 
PANIZZA, F. "Introduction: populism and the mirror of democracy". In: PANIZZA, Francesco, (ed.) Populism and the Mirror of Democracy. Phronesis. Verso Books, London, UK, 2005, p. 1-31.

PEREIRA, C.; MEDEIROS, A; BERTHOLINI, F. O medo da morte flexibiliza perdas e aproxima polos: consequências políticas da pandemia da COVID-19 no Brasil. Revista de Administração Pública, Rio de Janeiro, v. 54, n. 4, p. 952-968, Agosto. 2020. Disponível em:

http://www.scielo.br/scielo.php?script=sci_arttext\&pid=S0034-76122020000400952\&lng=en\&nrm=iso. Acesso em 18 Dez. 2020. Epub Aug 28, 2020. https://doi.org/10.1590/0034-761220200327.

PONCE, D. The impact of the coronavirus in Brazil: politics and the pandemic. Nat RevNephrol 16, 483 (2020). https://doi.org/10.1038/s41581-020-0327-0

PONTES, N. Produção de cloroquina coloca Bolsonaro na mira da Justiça.São Paulo, 2020. Disponivel em: https://www.dw.com/pt-br/produ\%C3\%A7\%C3\%A3o-de-cloroquina-coloca-bolsonarona-mira-da-justi\%C3\%A7a/a-54413561. Acesso em: 19 set. de 2020.

ROSENBERG E. S., DUFORT E. M., UDO T., et al. Association of treatment with hydroxychloroquine or azithromycin with in-hospital mortality in patients with COVID-19 in New York State. JAMA. 2020;323(24):2493-2502. doi:10.1001/jama.2020.8630.

SABINO, M.; BEHNKE, E., SOARES, J. Posse de Pazuello é marcada por defesa da cloroquina e crítica ao isolamento social. 2020. Disponível em: https://saude.estadao.com.br/noticias/geral,possede-pazuello-e-marcada-por-defesa-da-cloroquina-e-critica-ao-isolamento-social,70003440801. Acesso em: 15 dez. 2020.

SAID, D. 0 registro sanitário de medicamentos: uma experiência de revisão. Rio de Janeiro: INCQS/Fiocruz. Dissertação (Mestrado) - PPGVS, Rio de Janeiro, 2004, p. 156.

SCHMITH V. D., ZHOU J. J, LOHMER L.R. The Approved Dose of Ivermectin Alone is not the Ideal Dose for the Treatment of COVID-19. Clinical Pharmacology Therapheutics. 2020. https://doi.org/10.1002/cpt.1889.

SCOTT, Paul D.. Under Siege: The Rise of Right-Wing Populism or has the Demos Become Crazy?. Galáxia (São Paulo), São Paulo , n. 42, p. 5-22, Dec. 2019 . Disponível em: http://www.scielo.br/scielo.php?script=sci_arttext\&pid=\$1982-25532019000300005\&lng=en\&nrm=iso. Acessoem: 10 Dez. 2020. Epub Nov 07, 2019. http://dx.doi.org/10.1590/1982-25532019344235.

SINGH A.K., SINGH A., SHAIKH A., SINGH R., MISRA A.Chloroquine and hydroxy- chloroquine in the treatment of COVID-19 with or without diabetes: A sys- tematic search and a narrative review with a special reference to India and other developing countries. Diabetes MetabSyndr2020;14(3):241-6.

TAKAHASHI, T., LUZUM, J.A., NICOL, M.R. et al. Pharmacogenomics of COVID-19 therapies. npjGenom. Med. 5, 35 (2020). https://doi.org/10.1038/s41525-020-00143-y.

TOLEDO, L. F. Sem demanda, 400 mil comprimidos de cloroquina ficam em estoque no Exército. 2020. Disponível em: https://www.cnnbrasil.com.br/nacional/2020/11/16/sem-demanda-nos-estados400-mil-comprimidos-de-cloroquina-encalham-no-exercito. Acesso em: 17 dez. 2020. 
UOL. Hungria encerra polêmico estado de emergência pelo coronavírus. UOL, 2020. Disponível em: https://noticias.uol.com.br/ultimas-noticias/afp/2020/06/16/hungria-encerra-polemico-estado-deemergencia-pelo-coronavirus.htm Acesso em: 18 dez. 2020.

VARGAS, M. Saúde prevê gastar R\$ 250 milhões para pôr 'kit-covid' em farmácias populares. 2020.Disponível em: https://saude.estadao.com.br/noticias/geral,saude-preve-gastar-r-250-milhoespara-por-kit-covid-em-farmacias-populares,70003547892. Acesso em: 15 dez. 2020.

WORLD HEALTH ORGANIZATION (WHO). Coronavirus disease (COVID-19) outbreak. 2020. Disponivel em: https://www.who.int/emergencies/diseases/novel-coronavirus-2019. Acesso em: 24 set. 2020.

ZHAN X., DOWELL S., SHEN Y., et al. Chloroquine to fight COVID-19: A consideration of mechanisms and adverse effects?.Authorea. May 06, 2020. DOI: 10.22541/au.158872324.45525940.

\section{Notas}

${ }_{1}$ Para tanto, ver os trabalhos de Hawkins e Kaltwasser (2017), Levitsky e Ziblatt (2018), Norris e Ronald (2019), dentre outros. Para uma visão alternativa, ver Laclau (2013) e sua crítica por Nascimento (2018).

${ }^{2}$ Alguns consideram que esta prática tem simbiose com movimentos de revisionismo histórico. Durante a campanha, Bolsonaro afirmou que os negros africanos escravizados no Brasil durante o colonialismo "eram entregues pelos próprios negros", minimizando a responsabilidade dos brancos europeus.

\footnotetext{
${ }^{3}$ Para um artigo em língua portuguesa sobre a forma como Trump lidou com a pandemia e as consequências na opinião pública, ver Morais, Costa e Bernardi (2020).

${ }^{4}$ Campello e Zucco (2020) argumentam que esta estratégia é compreensível no caso de Trump, mas não no de Bolsonaro.
} 